\title{
guifi.net, a crowdsourced network infrastructure held in commons
}

\author{
Roger Baig, Ramon Roca ${ }^{\mathrm{a}}$, Felix Freitag, Leandro Navarro ${ }^{\mathrm{b}}$ \\ ${ }^{a}$ Foundation for the Neutral, Free and Open Network - guifi.net. Gurb, Catalonia \\ http://fundacio.guifi.net \\ ${ }^{b}$ Distributed Systems Group, Departament d'Arquitectura de Computadors, \\ Universitat Politècnica de Catalunya, Barcelona, Spain, \\ $h t t p: / / d s g . a c . u p c . e d u$
}

\begin{abstract}
Crowdsourced computer networks refers to network infrastructure built by citizens and organisations who pool their resources and coordinate their efforts to make these networks happen. Community networks are a subset of crowdsourced networks that are structured to be open, free and neutral. In these the infrastructure is contributed by the participants and is managed as a common resource. Many crowdsourcing experiences have flourished in community networks. This paper discusses the case of guifi.net, a success case of a community network daily used by thousands of participants, focusing on its principles and the crowdsourcing processes and tools developed within the community, the role they play in the ecosystem that is guifi.net nowadays, the current status of its implementation, its measurable local impact, and the lessons learned in more than a decade.
\end{abstract}

Key words: Community networks; crowdsourced networks; self-organized governance systems; self-provisioning; common pool resource; Do-It-Yourself

\section{Introduction}

Crowdsourced computer networks are built by citizens and organisations who pool their resources and coordinate their efforts to build network infrastructures. The coverage of underserved areas and the fight against the digital divide are the most frequent driving factors, but motivations such as contributing to develop a new telecommunications model or just for pleasure are also often mentioned by their contributors. Technologies used vary in great manner, ranging from very low cost off-the-shelf wireless (WiFi) routers to expensive optical fibre (OF) equipment [1].

Models of participation, organisation and funding are very diverse. For example, some networks are freely accessible, others are cooperative based, some are run by federations of microISPs, etc. Broadband for Rural North $\left(\mathrm{B} 4 \mathrm{RN}^{1}\right)$ in Lancashire, UK, or Nepal Wireless Networking Project $\left(\mathrm{NWNP}^{2}\right)$ are networks built in response to the lack of coverage of the conventional operators. B4RN deploys and operate optical fibre deployments in a cooperative way. NWNP [2] is a social enterprise that provides Internet access, electronic commerce, education, telemedicine, environmental and agricultural services to a number of remote villages, using wireless technologies. The French Data Network Federation $\left(\mathrm{FFDN}^{3}\right)$ is a federation of French Do-itYourself ISPs which comprises DSL resellers, WISPs, collocation centres and the like.

Community networks (CNs) is a subset of crowdsourced networks characterised for being open, free and neutral. They are open because everyone has the right to know how they are built. They are free because

Email addresses: \{roger.baig, ramon.roca\}@guifi.net (Roger Baig, Ramon Roca), \{felix, leandro\}@ac.upc.edu

(Felix Freitag, Leandro Navarro)

${ }^{1}$ http://b4rn.org.uk/

${ }^{2}$ http://www.nepalwireless.net/

${ }^{3}$ http://www.ffdn.org/en

Preprint submitted to Elsevier

June 13, 2017 
the network access is driven by the non-discriminatory principle, thus, universal. And they are neutral because any technical solution available may be used to extend the network and because the network can be used to transmit data of any kind by any participant, including commercial purposes.

Freifunk $\left(\mathrm{FF}^{4}\right)$ in Germany, the Athens Wireless Metropolitan Network $\left(\mathrm{AWMN}^{5}\right)$ in Attica, Greece, FunkFeuer $\left(0 \mathrm{xFF}^{6}\right)$ in Austria, Ninux.org in Italy, are examples of CNs with thousands of links, mostly wireless ${ }^{7}$, but gradually integrating also optical fibre and optical wireless links.

Although CNs have already been studied from several angles [3] [4], there is still insufficient understanding of the practises and methodologies which have given rise to such complex collaborative systems. This paper tackles this lack by analysing guifi.net ${ }^{8}$ [5] [6], the largest CN worldwide.

guifi.net started in 2004 as a group of people who met regularly for network planning and deployment. to find ways to create amateur networking infrastructures in remote rural areas, ignored or underserved by commercial ISP, taking advantage of open spectrum, open software and inexpensive WiFi devices. Along with the expansion of the network, the participants also debated about ways to structure the fast growing community. Bringing a network to new locations requires coordination for planning the links, configuring the hardware, aligning antennas, etc. In addition, new tasks such as planning the topology including a number of links, its capacity, coordinating routing, address allocation, etc. become more and more critical as the network and the community grow. That has resulted in many tools that have been developed specifically for guifi.net and are used by the guifi.net community. These tools are in constant evolution in order to better put the commons model into practice.

As result of our investigations, we firmly believe that guifinet has made very significant contributions not only to the formalisation of the CN concept itself but also to the development and application of effective social and technical tools to make them sustainable and scalable. In this paper we identify and analyse the most relevant of these tools and discuss about their impact on the expansion of guifi.net.

The remainder of this paper is structured as follows. Section 2 presents the underlying guifi.net principles that structure the participation and usage of the network, and how these result in a social production process of crowdsourcing that results in a collective good that is governed collectively as a common-pool resource $(\mathrm{CPR})$. Section 3 introduces the tools and strategies developed to support in implementing these principles, such as software tools to share information, communication among groups, coordinate contributions, oversee and regulate the community, stipulate collaboration agreements, resolve conflicts and compensate imbalances. Section 4 presents the results achieved in terms of the commons infrastructure, interconnection with other networks, the community of participants, the organisational framework and the measurable impact in areas with strong development. In Section 5 we analyse and discuss the results. Section 6 presents lessons learned that can be generalised. In section 7 some recommendations for future work are made. Finally, conclusions are presented in Section 8.

Computer networks are hereinafter referred as networks and network infrastructure as infrastructure.

\section{Principles}

The fundamental principles of guifi.net, revolve around i) the openness of access (usage) and ii) the openness of participation (construction, operation, governance) in the network.

Non-discriminatory and open access. The access is non-discriminatory because the prices are determined using the cost-oriented methodology (vs. market-oriented) with the fair-trade principle for labour pricing. It is open because everybody has the right to join the infrastructure.

Open participation. Everybody has the right to join the community. According to roles and interests three main groups can be identified: i) volunteers, interested in aspects such as neutrality, independence,

\footnotetext{
${ }^{4}$ http://freifunk.net/

${ }^{5}$ http://www. awmn.net/

${ }^{6}$ http://www. funkfeuer.at/

${ }^{7}$ The term wireless was broadly used to refer to this kind of communities, being wireless community networks (WCNs) the most common name, nevertheless, nowadays it is preferred to avoid the term for technology agnosticism

${ }^{8}$ http://guifi.net
} 
creativity, innovation, DIY, consumer's protection; ii) professionals, interested in aspects such as demand, service supply, stability of operation; and iii) public administrations, interested in managing specific attributions and obligations to regulate the participation of society, usage of public space, and even in satisfying their own telecommunication needs. A balance among these three groups must be preserved, as every group has natural attributions that should not be delegated or undertaken by any other.

The result of applying these principles result in a network that is a collective good, socially produced, and governed as a common-pool resource.

The network is a collective good or a peer property in which participants contribute their effort and contribute goods (routers, links and servers) that are shared to build the computer network, that combined by several Internet protocols result in a peer property, provided the community rules, as a community license, are respected by all participants.

The development of a community network is a social production: the development and its services is modular, as local communities willing to develop its local infrastructure can build their network islands according to the knowledge and principles of guifi.net, and as it expands, may merge with other guifi.net network islands. This is a cooperative process that with the right environment can be more efficient than a competitive market-based production. In some cases more feasible and even able to create an ecosystem where cooperative and competitive production can co-exist and co-develop. The network is quite modular, with nodes and links as the main building blocks. These modules can easily integrated in the network thanks to the addressing and routing protocols embedded in the computer network.

The governance of the network is based on the principles of a common-pool resource (CPR). Obviously the resulting system must be sustainable: a long-enduring CPR, given the social value of the infrastructure for the population involved.

\subsection{Network infrastructure as a Common Pool Resource}

The underlying principle behind guifi.net is the firm conviction that the optimal way to manage a network is doing it as a common pool resource (CPR) [7], being the network infrastructure the core resource, which is nurtured by the network segments the participants deploy to reach the network or to improve it, and the fringe unit is the connectivity they get. Eight principles are prerequisites for a sustainable CPR, and its application to our case, implemented with tools detailed in section 3, is described below:

Clearly defined boundaries. The principles of open and non-discriminatory access, and open participation in the life of the network translates into the community license, the Network Commons License (NCL), described in section 3.3, which prevents exclusion and regulates open and fair usage of the resource, including the traffic neutrality principle and the cost sharing principle. In addition there are specific collaboration agreements with professionals and third parties as described in section 3.3.

Rules regarding the appropriation and provision of common resources that are adapted to local conditions. The congruence between appropriation (usage of the network) and provision (expansion of the network) is mediated by the common network management and provisioning tools that assist in assessing the status of the network and its usage, and the tools to assist in the expansion of the network infrastructure covering the mapping of the nodes, configuration and even crowd-funding the cost of new or upgraded network nodes and links. These tools embody the principles defined by the Network Commons License.

Collective-choice arrangements that allow most resource appropriators to participate in the decision-making process. Complexity and transaction costs grow as the network grows in size (number of nodes, links, distance, participants). This complexity is managed by social structures such as the Local Internet Registry (LIR) operating the network (NOC) with diverse representation from all CPR stakeholders, and open structures as the local and global face to face meetings, and the digital participation tools such as social media and mailing lists. In all these structures the community of those who use or participate in the construction of the resource can participate openly, despite the members of the LIR and the patrons of the foundation depend of a core group of representative senior appropriators.

Effective monitoring by monitors who are part of or accountable to the appropriators. Monitoring is performed with the assistance of network management and provisioning software tools that 
provide a common information base about history and status of the common network infrastructure resource, and the lead of many local trusted senior members that rely on that open data and coordinate decisions when needed. These decisions are accountable, deliberated and reported in the common participation tools, and recorded in the organisational history as part of the extended community license.

Graduated sanctions for appropriators who do not respect community rules. The conflict resolution system, with clear and systematic methods to deal with users that negatively affect the common infrastructure resource, that typically occur due to imbalances between investment in the infrastructure and the network usage, mainly among professional members. The cost reporting is collected, publicly reported by the guifi.net foundation that is also in charge of the billing to compensate imbalances.

Conflict-resolution mechanisms which are cheap and easy of access. The conflict resolution system provides a structured procedure with three stages of escalation with progressive levels of complexity and economic cost to the parts, all driven by a lawyer chose from a set of volunteers. This system has been proven to be cheap, easily accessible, efficient, effective and scalable to address a range of conflicts around the network.

Self-determination of the community recognised by higher-level authorities. The community license has been checked by lawyers and written to be valid and enforceable under the Spanish legislation where guifi.net is mainly deployed. In addition, the guifi.net foundation has signed collaboration agreements with local and regional public administrations and is legally established for its function, also registered as a network provider or telecom service provider in Spain and member of the public market regulator, where it validates its service provision mechanisms.

In case of larger CPRs, organisation in the form of multiple layers of nested enterprises, with small local CPRs at their bases. The foundation mediates among the complex structures of internal members (such as individuals, professionals, service providers, public entities), the many local CPRs at the base, providing a federated CPR with many aspects in common, and interacts with external organisations in the local and global scope in many aspects.

The adaptive governance of the CPR depends on five principles:

Achieving accurate and relevant information, by focusing on the creation and use of timely scientific knowledge on the part of both the managers and the users of the resource. The community produces open knowledge about practices and experience, and works with the scientific community to co-develop and apply scientific knowledge for the best development, management and usage of the CPR. Collaboration agreements with academic and research organisation are the instrument to develop this principle.

Dealing with conflict, acknowledging the fact that conflicts will occur, and having systems in place to discover and resolve them as quickly as possible. The facts about the CPR are collected and managed by the Network management and provision tools. The rules in the community license and collaboration agreements define the limits that determine conflicting situations, quantified and discovered by inspection of the facts collected by the previous tools. The mechanisms for discussion are based on the participation tools where the conflicts are defined and then solved using instruments to reach consensus such as the conflict resolution system and finally the economic compensations system, and all coordinated by the guifi.net Foundation.

Enhancing rule compliance, through creating responsibility for the users of a resource to monitor usage. The openness principle requires users to publish open data about the network and allow the monitoring of nodes and its traffic. This requirement is supported and facilitated by the network management tools. The participation tools also help to facilitate any discussion and promote responsibility to the usage of the CPR.

Providing infrastructure, that is flexible over time, both to aid internal operations and create links to other regimes. The foundation provides that infrastructure and the flexibility to understand and adapt to changes over time, oversee the evolution of the CPR, facilitates the internal operation, and maintain links with external organisations and other regimes that coexist, interact an interoperate with the CPR.

Encouraging adaption and change, to address errors and cope with new developments. The foundation and his patrons, in its overseeing and steering role (sometimes referred as a second level or 
umbrella organisation), play this role of driving feedback, organisational learning and forecasting.

Some of the immediate benefits of this paradigm change are:

- Disappearance of the multiplicity of infrastructure because all participants operate on the same common infrastructure. The CPR defines means to reduce the transaction cost of sharing, promoting this practice.

- Increase of the efficiency of the infrastructure, as a consequence of the previous point. The utilization of the commons infrastructure is therefore higher.

- Costs savings, also environmental, as a consequence of the first point. Costs savings result from aggregation and resource sharing. Additional capacity can be obtained at the marginal cost of the required capacity, due to sharing, and not at the cost of deployment of additional infrastructure.

- Cost of access savings, not only due to the first point, but also because pricing is cost-oriented (fair trade oriented). That has positive economic spillovers in favour of digital services and more opportunities for local economic development.

- Empowerment of the citizens to bring the network where needed, severing the dependency on ISPs deployment plans.

- Universalisation of the access to the infrastructure, as a consequence of the two previous points.

- Creation of the required context for a true fair competition market of services.

Nonetheless, as any other CPR, community networks are fragile. More precisely, they are congestion prone, because connectivity is subtractable, and subject to the free rider problem, because they are intentionally non-excludable. Thus, efficient and effective governance tools are needed to protect the core resource from depletion, that is to say, to protect it from the Tragedy of the commons [8]. The network license, the conflict resolution procedure, or the economic compensations system are examples of these organisational tools. Collaboration tools and public information sets are particularly important in an organisation like this that is geographically distributed. Aside from the standard mailing list and WEB forums, guifi.net has developed a set of software tools to ease the design, deployment, management and operation of the network in a self-provisioning style. The main tools implemented to ensure the principles outlined in this section are described below.

\section{Implementation}

This section describes the tools and the roles of the participants that, according to our experience, play a critical role in the guifi.net ecosystem, that is to say, the essential set of means to put into practice the principles described previously. They are the result of the evolutionary and participatory development by the community and the formalisation of the community structure along the history of guifi.net, processes that generally have been undertaken in a rather reactive way, namely, as a response to specific problems as they appeared.

\subsection{Network management and provisioning software tools}

The community of guifinet has developed a set of software tools to ease the design, deployment, management and operation of the network in a self-provisioning style and supporting crowsourced efforts by members of the community given the intrinsic inter-dependence in the computer and social network. Most of them are integrated into the guifi.net website ${ }^{910}$. All tools have been developed following the Open

\footnotetext{
${ }^{9}$ The guifi.net website uses Drupal as CMS and MySQL as database. All the developed tools are presented as Drupal modules.

${ }^{10}$ https://guifi.net/en/guifi/menu
} 
Source model using a public collaborative development platform ${ }^{11}$ are publicly available under the GNU Public License ${ }^{12}$. Automation is essential to reduce the learning curve for participation and to avoid human mistakes. Consistent and comprehensive public data sets are essential to make the network implementable in the territory.

Network map tool ${ }^{13}$. Network planning requires maps and several tools to calculate distances, lines of sight, select neighbouring nodes and contact people in charge, etc. This tool combines geographic maps with network maps to collect and share all the knowledge about the network and the participants involved in it.

IPs assignment and routing configuration ${ }^{14}$. This is a back-office tool that takes care of IPs assignment and routing configuration. These procedures are fully automatised. The resulting information is stored in the main database.

unsolclic $^{15}$. The configuration of all routers is fully automatised. The human interaction has been reduced to copy $\mathscr{E}$ paste or reflashing procedures. This helps to avoid configuration errors that can create conflicts in the network, and ease the process of setting up nodes, which in turn promotes more participation.

Community Network Markup Language (CNML) ${ }^{16}$. The CNML is an XML specification developed in guifi.net through which the guifi.net database information is presented. All interactions should be done through it.

Network monitoring ${ }^{17}$. A fully distributed network monitoring system has been developed and implemented. It has been key to help the community to visualise usage, and identify problems or bottlenecks.

Network crowdfunding ${ }^{18}$. Since very early a tool was developed to coordinate the collection of voluntary contributions of money to fund new or upgrading nodes or links that could benefit directly or indirectly several users. The tool allows to create a proposal with a detailed plan with a description of the project, its cost and a deadline for contributions. If the target budget is met in the deadline the initiator will collect the money and launch the action. This mechanism has proven to be very successful to share costs among the community to upgrade bottleneck links or need for new nodes for the benefit of several citizens.

Expenditure declaration. This tool enables the declaration of expenditures, tracking and analysis of previous ones. It has been developed as part of the economic compensations system (describe in 3.5). It distinguishes between contributions made by professionals from those made by volunteers, treating the information accordingly.

\subsection{Communication tools}

Due to its technological nature collaborative tools of all kinds have flourished in guifinet. Predictably, almost all of them are free software and are hosted in servers of the community. The following are the most significant ones.

Website. It is the main participation and coordination tool. It integrates all the software tools described above, providing a complete platform for designing, deploying and operating CNs.

Mailing lists. Mailing lists ${ }^{19}$ is the preferred communication mean for discussion. There are global, territorial and thematic mailing lists. They are open by default ${ }^{20}$.

\footnotetext{
${ }^{11}$ https://gitorious.org/guifi

${ }^{12}$ http://serveis.guifi.net/debian

19 https://llistes.guifi.net/sympa/

${ }^{20}$ Closed mailing lists are just accepted in very justified situations.
} 
Social Media. A social platform ${ }^{21}$ has been put in place to handle documentation and discussions. Working groups are public by default but closed ones also exist to protect sensitive information.

Face to face meetings. Face to face meetings play a very specific role in strengthening social relationships. Local meetings are usually weekly or monthly based. In these meetings the participants work on their projects and help newcomers to join the group and the network. A global guifinet community meeting usually happens once a year, it is itinerant and always hosted by a different local group. The most relevant international CNs events are usually attended at least by one or two guifi.net members.

\subsection{Participation framework}

The following tools develop the legal framework for participation in the network.

Network Commons License (NCL) . The $\mathrm{NCL}^{22}$ is the license that any guifinet participant must subscribe. Its preamble ${ }^{23}$ sets the fundamental principles and the articles precisely establish the participant's rights and duties. It is written to be enforceable under the Spanish legislation. Legal certainty is essential to stimulate participation and investment, which in turn, is at the base of any economic activity. The license has been developed as part of a long lasting participatory deliberation process over several years, with contributions from many community members, reaching a consensus, revised and approved in several versions by the Foundation's Board. The initial version dates from January $2005^{24}$.

Collaboration agreements. Collaboration agreements are a set of standardised templates based on the experience of many specific agreements over the years. The number of specific agreements justified the standardisation process, which was led by the Foundation. The Foundation is always one of the signing parts. This way a web of trust is built having the Foundation as the hub. The agreements have the mission to grant the commitment of the parts to the NCL enhancing and strengthening the legal frameworks set by the license. Essentially there is subset of templates for the professionals that use guifi.net, one for the public administrations and another one for other collaborators such as universities and NGOs.

Professionals can choose between three options ${ }^{25}$ according to their level of commitment to the commons. Type A, full commitment, the preferred for the Foundation, implies that all the infrastructure deployed by a professional is contributed to the commons; type B, partial commitment, is for those professionals that just partially contributed to the commons; type $C$, opportunistic, the professional does not contribute any infrastructure to the commons (that is to say, they use what is available but does not contribute at all). The agreement implies the acceptance of a set of Service Level Agreements (SLAs) that orchestrate the coexistence among the professionals. Customised agreements are not accepted.

\footnotetext{
${ }^{21}$ http://social.guifi.net/

22 http://guifi.net/en/FONNC. Llicència de Comuns per a la Xarxa Oberta, Lliure i Neutral (XOLN) in Catalan http: //guifi.net/ca/CXOLN

${ }^{23}$ FONN Compact preamble:

- You have the freedom to use the network for any purpose as long as you don't harm the operation of the network itself, the rights of other users, or the principles of neutrality that allow contents and services to flow without deliberate interference.

- You have the right to understand the network and its components, and to share knowledge of its mechanisms and principles.

- You have the right to offer services and content to the network on your own terms.

- You have the right to join the network, and the obligation to extend this set of rights to anyone according to these same terms.

${ }^{24}$ http://guifi.net/ca/ComunsSensefils

${ }^{25}$ (Catalan) http://social.guifi.net/groups/guifi-coord/conveni-dactivitats-econ $\backslash \% \mathrm{C} 3 \ \% \mathrm{~B} 2 \mathrm{miques}-$ instal $\ \% \mathrm{C} 2 \backslash$ $\%$ B7lacions-connectivitat-i-manteniments-en-la.
} 
There is a single template for the Public Administrations. Although they often want to modify the template it is important to keep the texts as close as to the standard for the sake of homogeneity. The standard text is aimed at (i) alleviating the legal limitations of Public Administrations to participate in telecommunication activities as well as they avoid certain responsibilities, which fall outside of the scope of their standard tasks, specially for small and middle size administrations ${ }^{26}$, and (ii) orchestrate how they make their public resources available to the CN, thus, to all ISPs (e.g. those which do not want to contribute to the $\mathrm{CN}$ have access to this resources through the type $\mathrm{C}$ of the subset of agreements for professionals).

Finally, there are agreements with other entities such as universities or NGOs. Due to the small number of cases they have not been standardised yet.

\subsection{Participants}

A clear classification of participants helps to avoid misunderstandings and conflicts of interest. The formalisation process in guifi.net has also lead to the follwoging groups.

Volunteers. Anyone has the right to join the project as a volunteer with the sole obligation is to fulfil the NCL. Volunteers have a key role in preserving the spirit of the project, thus, its neutrality, its targets, etc. They have the right to declare their contributions to the expenditure system and the rest of the tools of the Foundation aimed at this group.

Professionals. Professional is anyone, including legal entities (i.e. companies), engaged in economic activities involving guifi.net infrastructure, being ISPs and installers the standard cases. To be able to carry out such activity is mandatory to sign a professional agreement with the Foundation. Once the agreement is signed, the professional is included in the economic compensations system and is allowed to benefit form the Foundation specific tools for the operators (e.g. wholesale Internet access, Local Internet Registry, Internet eXchange point participation) in addition to the tools available for the volunteers.

The Foundation. The guifi.net Foundation (Fundació Privada per a la Xarxa, Lliure i Neutral guifi.net) is the reference organisation that was created by the guifi.net community to give a legal identity to the guifi.net project. Its foundational mission is to protect and promote the networks held in commons. To protect the network, it maintains the NCL and enforces its compliance when necessary. The promotion activities include the development of strategic and innovative projects, the operation of critical parts of the network infrastructure, dissemination tasks, etc. It has a set of tools (e.g. IP address space, legal identity, possibility to operate under its name) available to anyone who wants to contribute to expand the network, professionals included. It also does many dissemination activities. The Foundation is composed by the Board of Directors (unpaid) and the workers. It is funded from the services it gives to the professionals (e.g. activities in the Network Operation Center (NOC), operation of the economic compensations system) and from specific projects to which it may participate (e.g. research projects, consulting activities). The Foundation plays a vital role for the coordination and management of the guifi.net ecosystem. Nonetheless its power is rather limited because, as the rest of the participants, it just owns the part of infrastructure it has contributed, and all its actions are constrained to its foundational mission of coordination and arbitration. Thus, its authority is mostly reputation based.

Public administrations. The participation of the Public Administrations is necessary because the have the responsibility to regulate the public goods and to contribute to the social development and CNs relay on of both of them to carry out their activities. In addition Public Administrations contribute to the CN satisfy their telecommunication needs.

Third parties. Other organisations that have interest in the CN, such as NGOs or universities.

\footnotetext{
${ }^{26}$ In the European Union as well as in most of the Western countries, telecommunications is a public service that must be delivered by the private sector. In this context, the room for manoeuvre in public administrations is limited to very specific actions (self-provisioning, undeserved areas, etc.) and under very special conditions (separate account, self-financed, etc.)
} 


\subsection{Governance tools}

These are the socio-economic tools the project has developed to keep the infrastructure and the project itself operational. The Foundation is responsible to keep these tools in place.

Conflicts resolution system. A systematic and clear procedure for resolution of conflicts with a scale of graduated sanctions has been developed ${ }^{27}$. It consists of three stages, conciliation, mediation and arbitration, all of them driven by a lawyer chosen from a set of volunteers. The cost of the procedures is charged to the responsible part or to both parties in case of a tie. This system has developed from the experience and has defined in a precise manner to help in addressing these conflicts in a quick and standard way, with help from lawyers, and scalable for a growing community. It was developed in a moment were the flame wars between few participants threatened the whole project. The Foundation had to take a leading role in its development and implementation.

Economic compensations system. The economic compensations system has been developed and implemented to compensate imbalances between investment in the commons infrastructure and network usage among the professionals. Expenditures declared by the professionals are periodically cleared according to the network usage. The calculations are done by the Foundation and are made available to the professionals. The Foundation centralises and manages the billing system (each professional only makes or receives a single payment). A typical income for the Foundation is a percentage depending on each professional type is charged to the result of these calculations ${ }^{28}$. In addition professionals are allowed to charge a reasonable amount for opportunistic connections ${ }^{29}$ until their investment is covered.

\section{Results}

In this section we present the most relevant results of the guifi.net project. First we analyse the commons infrastructure. Its physical parameters can be perfectly quantified thanks to the CNML network database and the information on its web site. Nonetheless costs must be estimated because the software tool for reporting the expenditures has just been put in place recently. The description of the interconnection to other network infrastructure follows. In this case the costs can be established with a high level of precision, since the information about most of them is shared between the Foundation and the operators. Regarding participation, the data presented is rather qualitative because, due to the openness of the project, only indirect metrics can be quantified. The description of the impact of the project is based on third parties' information.

\subsection{The commons infrastructure}

Currently, at physical level, guifi.net combines several technologies being the wireless and the optical fibre the most common. Due to its affordability, accessibility and ease of deployment, WiFi was the first technology to be used and is still the most popular, up to the point that it is considered fully integrated into the ecosystem (i.e it is fully supported by the web tools and its use is widespread among professionals and volunteers). The initial nodes of guifi.net were deployed by 2004. Figure 1a depicts the evolution of the total operational nodes over time. Optical fibre was first introduced in $2009^{30}$.

As of 21 September 2014, guifi.net has a total of 40,704 nodes, 25,774 of them declared as operational, accounting for 29,893 WiFi links (27,338 AP-Client and 2,554 Poin-to-Point) making a total length of $48,106 \mathrm{Km}$. Most of the nodes, 40,468 of the total, are located in Spain. Figure 1b shows their distribution on the map. Figure 2 shows two cases of implementation at city level (general views at the top and details views at the bottom).

\footnotetext{
${ }^{27}$ http://social.guifi.net/groups/guifi-legal/reglament-dels-procediments-de-resoluci $\%$ C3 $\ \%$ B3-de-conflictes

${ }^{28}$ Type A $10 \%$ (to cover administrative costs), Type B 50\%, and Type C $100 \%$.

${ }^{29} \mathrm{~A}$ client node that connects in a DIY manner to a supernode that has been paid by a professional.

${ }^{30}$ http://guifi.net/node/23273
} 


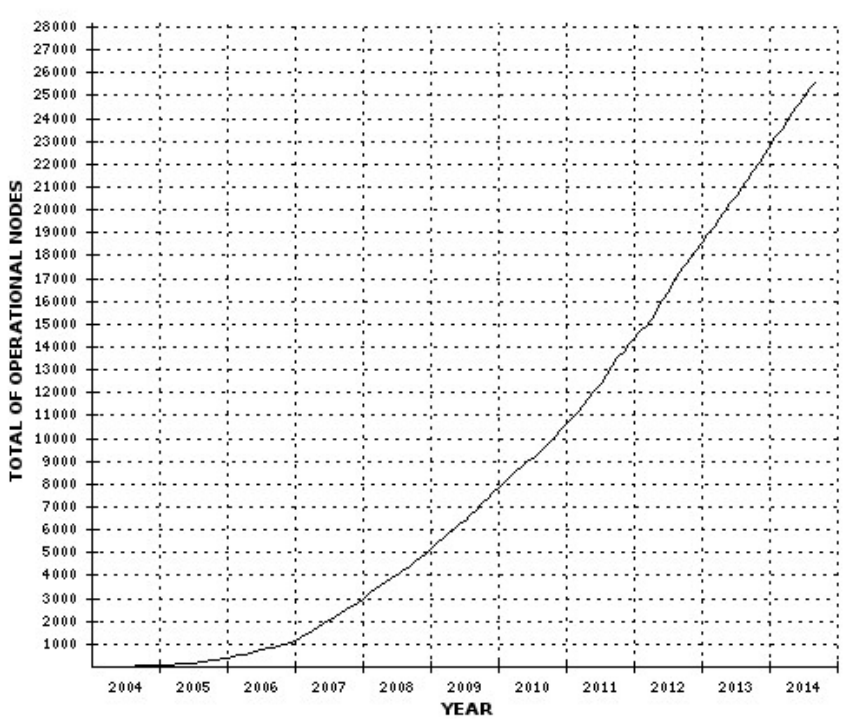

(a) Growth in total number of operational nodes.

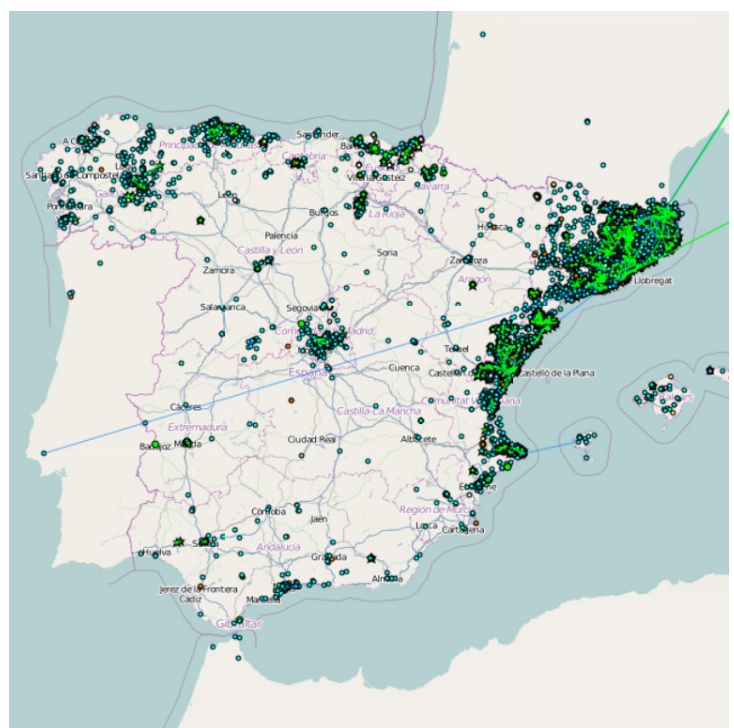

(b) guifi.net deployment (Sep. 2014).

Figure 1: guifi.net summary

As regards to optical fibre, due to the fact that registration of this type of link is not yet in production 31 , at the moment the numbers can only be estimated by alternative means. We estimate around $100^{32}$.

Topologically speaking, WiFi and optical fibre networks are rather similar [6]. In both cases end-usernodes (the nodes) are connected to a central point (the supernodes in WiFi and the PoPIX -Point-of-Presence Internet Exchange- in optical fibre $)^{33}$, and supernodes are connected to each other through dedicated links forming the backbone. In WiFi practically all links are deployed by guifi.net members. In contrast, in optical fibre deployments most of the PtP links are subcontracted dark fibres ${ }^{34}$. Figure 3 shows the current distribution of the operational PoPIX (15 in total). In the areas where the two technologies coexist, optical fibre links are replacing WiFi ones in the backbone and these a forming a backhaul resulting in a more efficient topology ${ }^{35}$. The economic compensations system is applied at PoPIX level. The metric used to quantify the network usage is the percentage of the total aggregation of inbound and outbound traffic to networks that are not held in commons (i.e. traffic to and from the NIX or to the carriers).

According to guifi.net Foundation estimations presented in Table 1 and Table 2, the estimated capital expenditure (CAPEX) of the infrastructure built in commons is already over $6.5 \mathrm{M} €$ and its estimated Operating expenditure (OPEX) around 208,400 $€$ per month, that is to say, over $2.5 \mathrm{M} €$ per year.

At the IP level, guifi.net uses IPv4 RFC1918 private addresses. IPs assignment was initially made respecting Free networks ${ }^{36}$ allocation, but currently the full 10/8 address space is considered, although in

\footnotetext{
${ }^{31}$ This feature, which involved redesign and an significant amount of new code, was developed in summer 2014 is expected to be in production in early 2015. The large amount of optical links already deployed will require additional time to register all this data.

${ }^{32}$ This estimation has been made with information contributed by each ISP and cross-comparing responses with the amount of transit and the amount of IPs assigned

${ }^{33}$ In WiFi the so called infrastructure mode (i.e. the combination of master-client mode for nodes to supernode connections and dedicated Point-to-Point -PtP- links between supernodes) has shown to be much more efficient than solutions based on IEEE802.11 Ad-Hoc mode. Nonetheless some parts of the network operate in Ad-Hoc mode.

${ }^{34}$ So far all to the Catalan national dark fibre provider http://www.xarxaoberta.cat/en/about-xoc

${ }^{35}$ Amending the abnormal situation of a backbone of several tenths of WiFi hops.

${ }^{36} \mathrm{~A}$ project started by the 2000 intended at harmonising the $10 / 8$ block allocation among CNs. It is been unmaintained since years.
} 

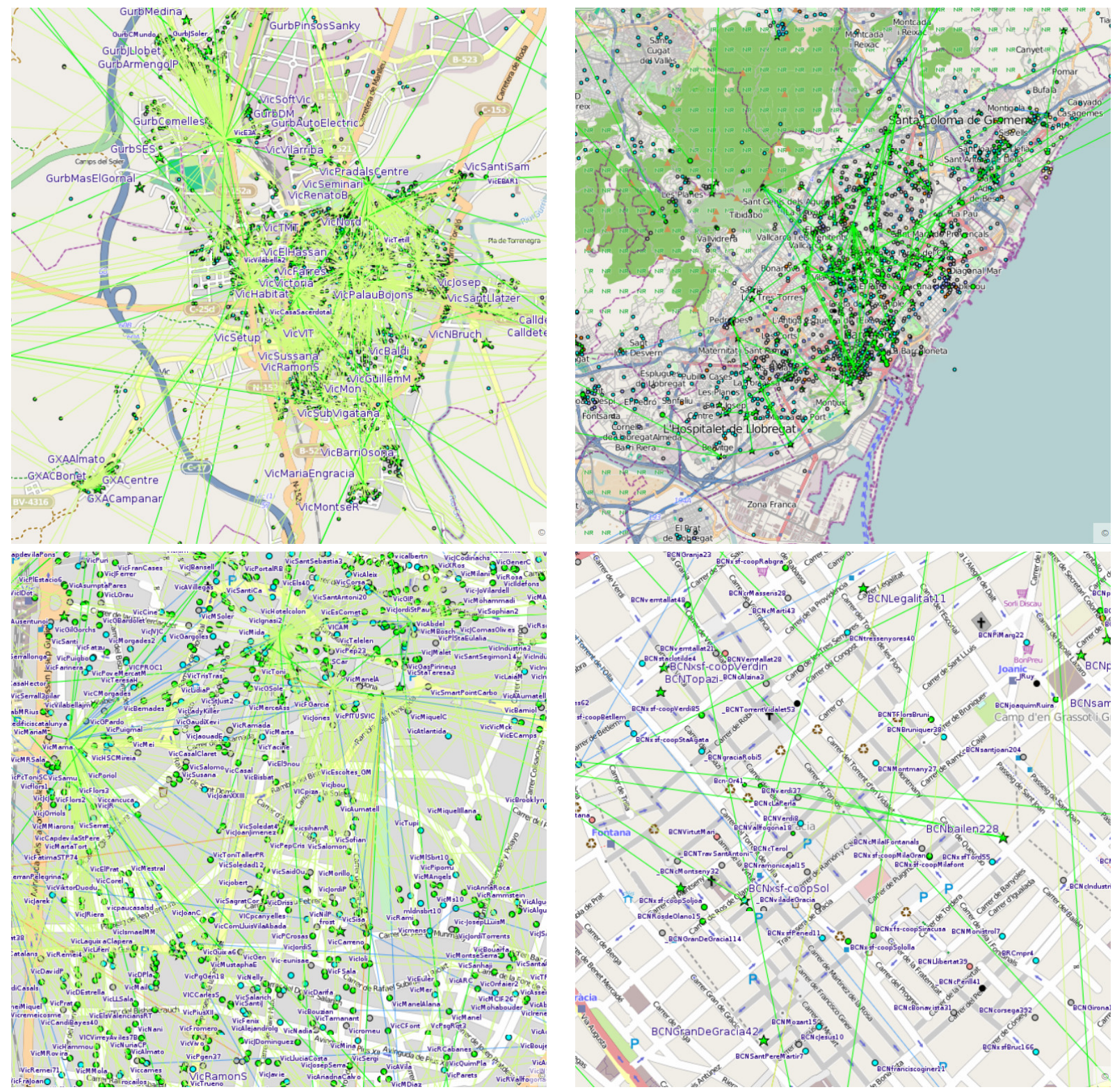

Figure 2: guifi.net maps (Sep. 2014). Cities. Left: Vic. Right: Barcelona. Top: general. Bottom: detailed.

practice just few $/ 16$ blocks are being used ${ }^{37}$. IPs are allocated to supernodes in $/ 27$ chunks ${ }^{38}$ and nodes receive one of these IPs each. In addition, the 172.16/12 block $^{39}$ chunks is used for the PtP backbone links. Nonetheless this range is not routed, hence 10/8 and 172.16/12 address are frequently referred as, respectively, public addresses and private addresses.

At the routing level, the network is split into Autonomous Systems, most of them internally running OSPF, interconnected via BGP. Numbers and names assignments and allocations are made foreseeing the

\footnotetext{
${ }^{37}$ Geographical allocation.

${ }^{38}$ Such small netmask is a legacy of the address space scarcity of the times of Free Networks (10/8 were assigned to each CNs regardless its size -while guifi.net already had thousands of nodes the other CNs had tens at most).

${ }^{39}$ At the time of writing just the 172.25/16 block is used. Assignments are made in $/ 30$.
} 


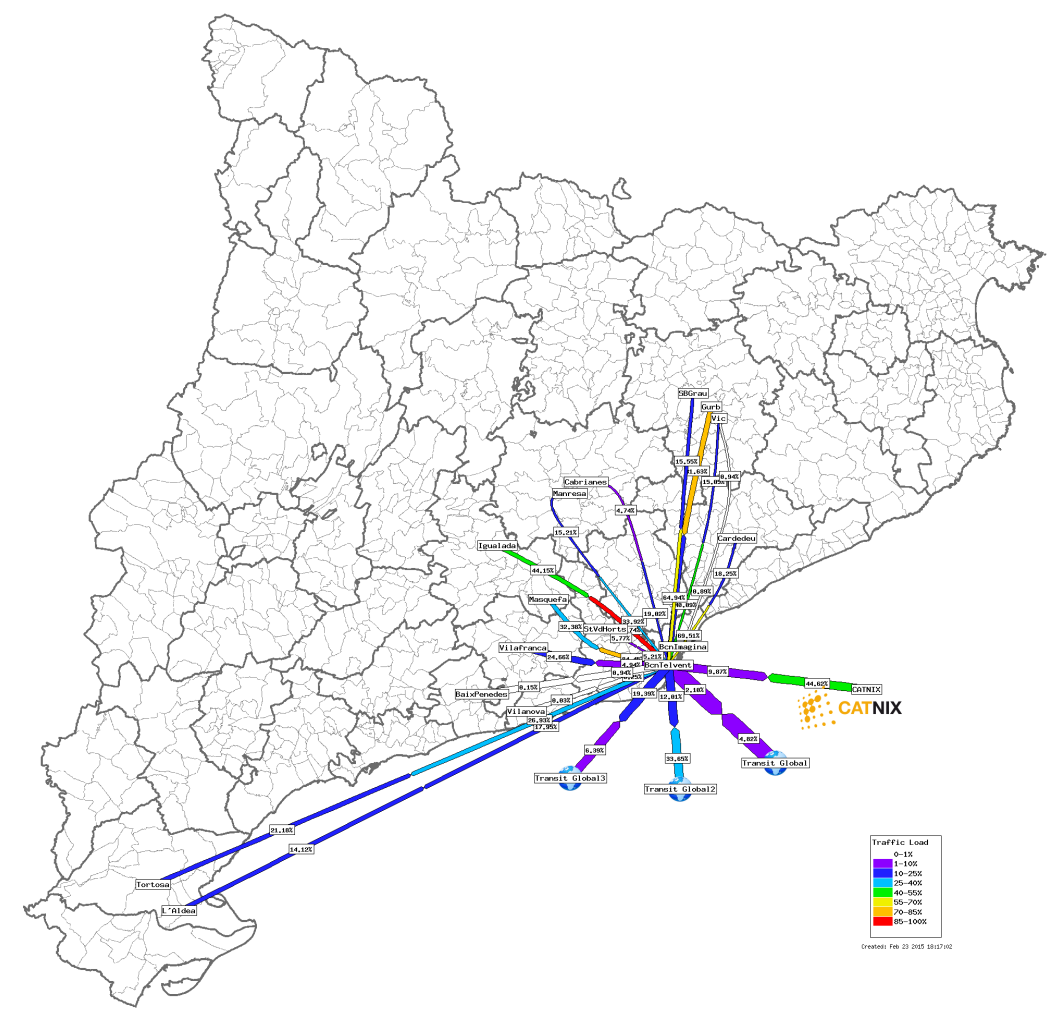

Figure 3: guifi.net Optical Fibre backbone links (Jan. 2015). The thickness of the lines is a function of the capacity of the links, from 100mbsto $10 \mathrm{Gbs}$. 
Table 1: guifi.net CAPEX estimation (Sep. 2014)

\begin{tabular}{llrrr} 
& & $\begin{array}{r}\text { Quantity } \\
{[\mathbf{u n i t s}]}\end{array}$ & $\begin{array}{r}\text { Estimated } \\
\text { average cost } \\
{[\boldsymbol{€} / \mathbf{u .}]}\end{array}$ & $\begin{array}{r}\text { Total } \\
{[€]}\end{array}$ \\
\hline & WiFi node & 25,500 & 250 & $6,375,000$ \\
& OF node & 100 & 250 & 150,000 \\
& PoPIX & 12 & 2,750 & 33,000 \\
\hline Commons & & & & $\mathbf{6 , 5 5 8 , 0 0 0}$ \\
& PoPIX & 12 & 2,750 & 33,000 \\
\hline Interconnection & & & & $\mathbf{3 3 , 0 0 0}$ \\
& & & & $\mathbf{6 , 5 9 1 , 0 0 0}$
\end{tabular}

Table 2: guifi.net OPEX estimation (Sep. 2014)

\begin{tabular}{|c|c|c|c|c|}
\hline & & $\begin{array}{r}\text { Quantity } \\
\text { [units] }\end{array}$ & $\begin{array}{r}\text { Estimated } \\
\text { average cost } \\
{[€ / \mathbf{u} / \text { month] }}\end{array}$ & $\begin{array}{r}\text { Total } \\
{[€ / \text { month }]}\end{array}$ \\
\hline & WiFi node & 25,500 & 8 & 204,000 \\
\hline & OF node & 100 & 8 & 800 \\
\hline & PoPIX & 12 & 300 & 3,600 \\
\hline \multirow[t]{12}{*}{ Commons } & & & & 208,400 \\
\hline & Proxies & 100 & 60 & 6,000 \\
\hline & PoPIX & 12 & 300 & 3,600 \\
\hline & CATNIX & 1 & 600 & 600 \\
\hline & Uplink & 2 & 1,000 & 2,000 \\
\hline & Colo Bar & 1 & 1,500 & 1,500 \\
\hline & Colo Vic & 1 & 200 & 200 \\
\hline & RIPE-NCC & 1 & 150 & 150 \\
\hline & Provi. & 1 & 4,000 & 4,000 \\
\hline & admin. & 1 & 1,500 & 1,500 \\
\hline & techn. & 1 & 1,500 & 1,500 \\
\hline & Insura. & 1 & 70 & 70 \\
\hline Interconnection & & & & 11,050 \\
\hline
\end{tabular}

network as a whole single network (i.e. respecting compatibility). As of September 2014 about 2,900 routes are announced at the biggest BGP cloud ${ }^{40}$.

\subsection{Connection to other networks}

guifinet is connected to many networks, including the global Internet, in a number of ways. The preferred way is by peering with other networks, because is closely aligned with the cooperative principles of the project. Less preferred ways, but also possible and currently used, are through paid carriers and by sharing domestic Internet connections. Network interconnection is conceived as content, so as such, it is made available according to the conditions of the one who offers it.

The guifinet Foundation is member of the Catalan Exchange Point $\left(\right.$ CATNIX $\left.^{41}\right)$, which has about 39 peers (counting IPv4 and IPv6) and has three internet uplink from independent providers: one at 10Gbs, another one at $1 \mathrm{Gbs}$, and the last at 300mbps. The capcity of the uplinks and the CATNIX connections are distributed to the ISPs, which in turn distribute them among their customers. Figure 4 shows the evolution of the total inbound and outbound guifi.net transit over the last year. In addition most of the operators have retail public IPv4 and IPv6 ranges distributed in the same way. The network is also connected to the

\footnotetext{
${ }^{40}$ Because block aggregation is not automated

${ }^{41}$ http://www. catnix.net/en/
} 


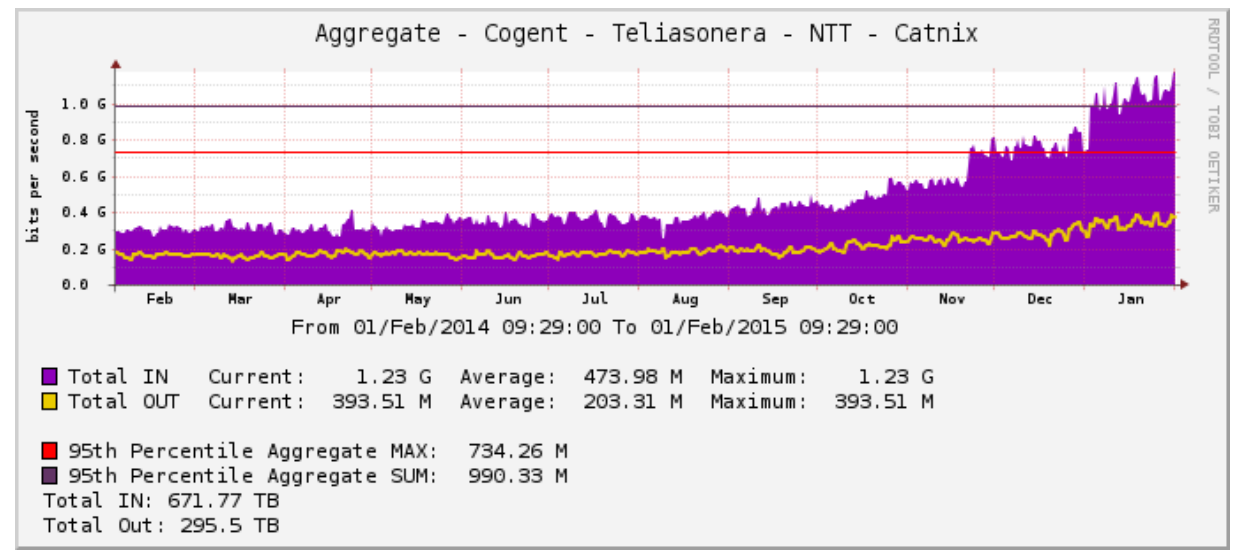

Figure 4: Total inbound and outbound guifi.net transit (Feb. 2014 - Jan. 2015). Aggregation of the traffic with the peers of the IX (CATNIX) and the traffic of the three upstream providers.

Community-Lab.net experimental testbed and as part of that guifi.net has a network level federation with several other European CN.

The standard way for users to make their domestic Internet connections available to other guifi.net members is through proxies. guifi.net has developed a federation of Internet access proxies which allow each user to use all of them with the same credentials and for free. DSL lines of public administrations (councils, libraries, telecentres, etc.) are usually made available to guifi.net participants through this way because it offers several technical and, most important, legal guarantees.

According to the estimates made by Foundation the CAPEX of the interconnections is around 33,000 $€$ and the OPEX over 132,600 € per year.

\subsection{The participants}

As already indicated, the guifi.net ecosystem is very rich in terms of variety of participants, each of them playing an strategic role. A recent study [9] in 2014 found 13,407 registered users in the guifi.net portal and 55 mailing lists. A description of the current state of the most relevant groups follows.

Volunteers. As for most open projects, the number of volunteers can merely be quantified by indirect metrics such as number of posts in the mailing lists, etc. but qualitatively we can say that the guifi.net community of volunteers is healthy. Volunteers contribute in many tasks such as bootstrapping new areas, assisting newcomers, improving the software tools, doing maintenance, etc. Thanks to their locality and their commitment to the project they are a key component in the task of controlling that the rules are fulfilled, specially in areas where the Foundation presence is limited. As an indicator of size apart from the 13,407 registered portal users, there are 40 regional mailing lists.

Professionals. There are nine SMEs participating in the economic compensations system. In addition there are many SMEs and self-employed people that carry out installations and other paid activities related to guifinet ${ }^{42}$. Despite the fact that competition for customers is always a (desired) source of tension, which occasionally leads to conflicts, we can state that the coexistence is positive and the level of collaboration is rather high. As an indicator of size, the professionals mailing list has 270 subscribers.

The Internet access is still the most popular service. Nonetheless, others such as VoIP and remote backups have also been offered since long time ago and, new services such as video streaming and video on-demand are becoming popular, specially in the areas with optical fibre. The professionals offering infrastructure services are commonly referred as installers and content providers as operators.

\footnotetext{
${ }^{42}$ https://guifi.net/en/node/3671/suppliers
} 
The Foundation. The guifi.net Foundation was set in July 2008. It was created to give a legal entity to the guifi.net project and to be a reference for it. Putting tools to stimulate the expansion of the network in place is one of its main tasks. To this end it has become member of the CATNIX as well as of the RIPE-NCC ${ }^{43}$ from which it has obtained the following resource: ASN 49835, IPv4 109.69.8.0/21, 5.10.200.0/21 and 185.32.16.0/22, IPv6 2a00:1508::/32. From the legal point of view, through the corresponding notification to the Spanish National Regulatory Organisation ${ }^{44}$, it is the operator of the network infrastructure by default (i.e. of those parts of the network which are not operated by anyone else) which is very convenient for participants who are not familiar with these specific legal and administrative details of the telecommunication sector such as volunteers or public administrations.

As part of its actions to stimulate the economic activity on the one hand, the Foundation promotes network projects (e.g. an optical fibre deployment in a neighbourhood) which afterwards are executed by the professionals (project allocations are done according to pre-established rules and the Foundation always keeps the role of project supervisor) and on the other hand it helps these professionals by sharing its resources, specially when they start, and accompanies them during their growth process.

Its dissemination activities include promotion in public administrations, politicians, private companies and citizens, dialogue with the regulator and response to any public call that may effect the commons network, etc.

Its research activities are mostly tied to collaborations with universities. The Foundation has participated (period 2011-2015) in two FP7 projects and one CIP project of the European Commission.

Other guifi.net organisations. A diversity of non-profit organisations complement the activity of the guifi.net Foundation. Local associations of users are usual, some having legal identity ${ }^{45}$ and others being just informal groups. Some of these groups are former wireless communities that joined guifi.net, many keeping their identity ${ }^{46}$. Cooperative initiatives ${ }^{47}$ have also emerged and have started promoting projects.

This kind of organisations are usual entry points for newcomers since they do a lot of dissemination activities and support to beginners. Associations and informal groups are preferred by technical skilled people while cooperatives are preferred by people who supports guifi.net principles and ideas but either they do not have the required skills or the time to put them into practice. There are two associations participating in the economic compensations system.

Grup LIR (GLIR) It is the technical group in charge of operating the Guifi NOC. It consists mostly of professionals, but volunteers also have the right to participate. Currently there are 42 persons. The group is closed to protect sensitive information.

Public administrations. As in any other infrastructure, public administrations have strategic roles (policy making, promotion, etc.) in the telecommunications sector. Thus, collaboration is almost mandatory. guifi.net has signed collaboration agreements with many of them, mostly small to middle size municipalities (e.g. with almost all of the Osona county), but also with counties (e.g. Consell Comarcal d'Osona). A correlation between size of municipalities and the level of commitment with the commons network can easily be identified, the smaller and the less served by conventional telcos, the stronger the commitment and the bigger the contributions. At the moment more than hundred councils are actively collaborating with guifi.net, most of them through the Foundation and local installers and operators.

Universities. The Foundation has signed collaboration agreements with almost all Catalan universities. Collaboration activities include infrastructure deployment, research projects, students mentoring, dissemination, etc.

\footnotetext{
${ }^{43}$ http: //www.ripe.net/

${ }^{44}$ Comisión del Mercado de las Telecomunicaciones (CMT), http://cmt.es/

${ }^{45}$ E.g. Associació per a l'expansió de la xarxa oberta, E.g. Delegació territorial de la Fundació al Maresme

${ }^{46}$ E.g. Badalona Wireless, Gràcia sense fils, Pineda sense fils, etc.

${ }^{47}$ E.g. Sestaferia.net, Eticom/somconnexió, Guifi Baix, etc.
} 
Other third parties. The following are examples of the many cases of successful collaborations with third parties to contribute to the network commons. These cases show that almost any entity or organisation can contribute. Since 2008 the Catalan top level domain (.cat) has most of its hardware in the guifi.net facilities; their contribution was crucial to launch the first PoPIX. The Hospital of Vic ${ }^{48}$ self-supply its connectivity needs through an optical fibre cable deployed by it and held in commons.

\subsection{Governance}

Conflict resolution system. There have just been three cases of conciliation since the conflict resolution system has been put in place in 2013. The number of flames in the forums and in the mailing lists has been substantially reduced.

Economic compensations system. The compensations system was started in the Barcelona PoPIX in April 2014. The second one, Bages, will be started in October and the plan is to extend it to the rest of guifi.net during 2015 .

\subsection{Impact}

Figure 5 presents the data about penetration of the bandwidth and Internet access penetration in the households of Catalonia per in 2013 released by the public Catalan Statistics Institute (Institut Català d'Estadística (IDESCAT) ${ }^{49}$ ) per county [10]. It also contains the Internet access average rate of Internet access of the European Union, Spain and Catalonia. The first thing to notice is that, despite the fact that Catalonia is about three points above Spanish average, it is still seven points below the European average. Second, and most relevant regarding guifi.net impact, the Catalan county with the best results and the only one above EU average, is Osona, where guifi.net was born. Moreover, it is the only county where broadband access is above Internet access. The indicators of other counties where guifinet presence is significant such as Bages or Baix Ebre are also above when compared to similar counties but where guifi.net presence is irrelevant.

Osona has about 9,000 nodes ${ }^{51}$. Combining this number with others coming from IDESCAT ${ }^{52}$, we conclude that about $22,4 \%$ of the Osona inhabitants have guifinet access: around 30,500 people.

\section{Discussion}

Over 25,000 operational nodes deployed in ten years, with an estimated CAPEX over 6.5M $€$ and an estimated OPEX over $2.7 \mathrm{M} €$ per year, are sufficient indicators to state that the guifi.net case proves that telecommunication infrastructures can be held in commons and also that $\mathrm{CNs}$ have a great potential to bootstrap the local economy.

The heterogeneity of the technologies used as well as of the participants and the level of collaboration among them reinforces the previous statement. The nurtured community of participating volunteers evidences that the project is truly open. The number of professionals evidences that it provides business opportunities ensuring its sustainability. The amount of municipalities involved shows its social value. The guifi.net community is characterised by a high self-awareness and a general will to push the project forward. All this is done following a very successful crowdsourcing model, based on contributions from a large community of more than 13,000 members and a set of organisational structures, agreements and support tools, with only a couple of part time employees devoted to these tasks.

\footnotetext{
${ }^{48}$ The capital of the Osona county.

49 http://www.idescat.cat

${ }^{51}$ http://guifi.net/ca/Catalunya, 8,958 adding Osona and Lluçnȩs and substacting Santa Maria de Marlès and Sant Feliu Sasserra as they belong to other counties (comarques).

${ }^{52}$ Osona has 71,597 households, Catalunya 2,944,944 http://www. idescat.cat/pub/?id=aec\&n=700; in Osona 38,029 buildings have at least a household, $75.6 \%$ of the households are single family houses http://www.idescat.cat/pub/?id=aec\&n= 692\&lang=en; Osona population (2013): 155,069 http://www.idescat.cat/pub/?id=aec\&n=246\&lang=en; thus, 4.08 inhabitants/building. Rate of 0.1 supernodes to nodes; estimation half of them not installed in homes.
} 


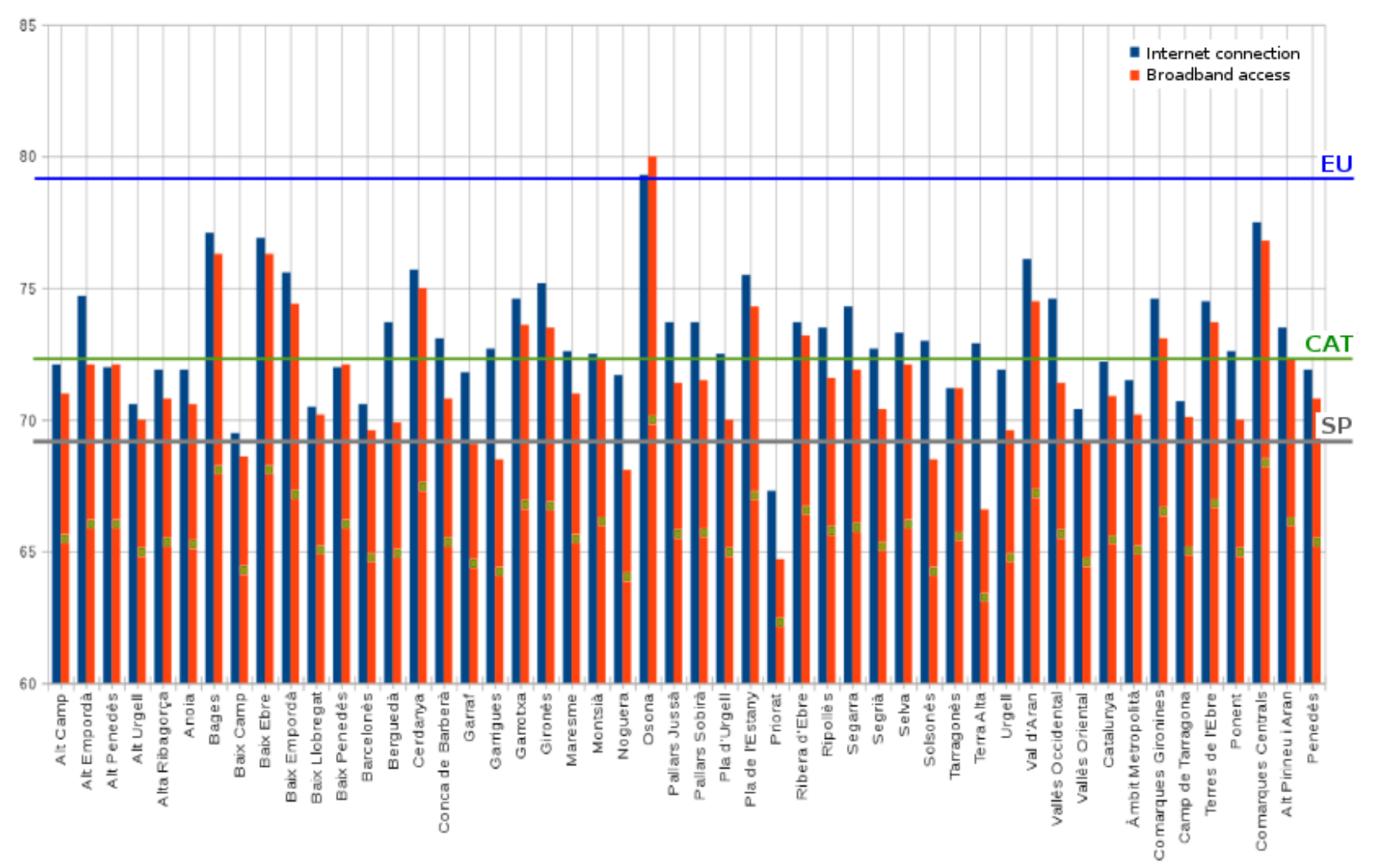

Figure 5: Households bandwidth and Internet access in Catalonia per county (comarca) in 2013. Source: IDESCAT 50

Considering that the number of new nodes of the last year is over 4,500 (Figure 1a), the amount of small and middle network clouds (Figure 1b), and that a region that has adopted guifi.net, Valencia, already accounts for over $17 \%$ of the nodes, we can say that guifi.net is a successful crowdsourcing project that has a real impact on society (Figure 5).

Collaboration from public administrations is crucial in the effective development of guifi.net by the community. It becomes clear when comparing the guifi.net penetration in the cities of Vic and Barcelona (Figure 2), both cities with more than one conventional operator available. Indeed, despite that the Vic council commitment has never been as strong as the commitment of smaller municipalities of the Osona county, it has treated guifi.net rather decently (e.g. signed the agreement with guifi.net, given similar treatment as to the conventional operators but understanding its traits). On the contrary, the collaboration with the Barcelona council has never succeeded. The results are not only evident in terms of operational nodes, 1243 to 329, although Barcelona has about forty times the population, but also in terms of rates such as planned to operational nodes ${ }^{53}, 0.32$ to 0.60 , or nodes to supernodes, 0.02 to $0.3^{54}$.

Answering why guifi.net has started in Osona and not somewhere else and why it has had such spectacular evolution requires a detailed discussion. The fact of being under the European regulatory framework has obviously been an enabler. The state of the art of technology helps to explain when it started (i.e. after WiFi became affordable and hackable) but fails to answer why precisely in a Catalan county because there are older European wireless initiatives (e.g. FF dates from 2000). We believe that the key factors are the vision of the starters in applying the commons concepts to the infrastructure to be designed and deployed, combined with the fact that they had the background and they committed enough efforts to implement their ideas.

\footnotetext{
${ }^{53}$ This rate is an indicator of the loss of opportunity, i.e. people that would join guifi.net if it were easier.

${ }^{54}$ This rate is an indicator of the participants' commitment, specially when combined with the planned to active nodes rate, i.e. those who are in the network are committed enough to afford a supernode.
} 
Undoubtedly, the self-service approach, the understanding that the existence of a solid economic activity is essential for the sustainability of any project, the evolutionary approach for solving the problems are additional reasons.

It is interesting to notice that CNs can perfectly coexist with the conventional network operators. Figure 5, shows that not only CNs contribute to ameliorate digital exclusion, but they do not replace conventional operators. According to IDESCAT, in 8.54\% of the households the price is a reason for not having Internet access ${ }^{55},{ }^{56}$, which matches the differences in Figure 5 between Osona and Selva ${ }^{57}$. In this regard, while a few guifi.net participants have cancelled their contracts with conventional operators, they are more than exceeded by those participants who have also Internet provision contracted from conventional operators, among others reasons because guifi.net alone may not fulfil all their needs, or simply complement guifi.net.

\section{Lessons learned}

This section discusses what, to our understanding, are the main lessons learned. Base on our active participation and research on guifi.net, and in comparison to other community networks, this patchwork of loosely connected ideas and practises is intended to be a comprehensive set of guidelines for other projects. We strongly recommend these projects to build upon what exists already, to devote their efforts in refining it and to contribute back their improvements.

Open and non-discriminatory access. Although these concepts are implicit to CNs it is essential to safeguard them, thus, it is good to make them explicit. guifi.net has demonstrated its success in providing access to infrastructure in areas where other traditional infrastructure provision models haven't been available or effective.

Early adoption of a network license. The existence of such a precise framework for participation has shown to be very effective in focusing the community efforts and in creating an appropriate environment for business development and local investment. It is important to notice that (i), to the best of our knowledge, guifi.net is the only CNs with such well-defined rules and it much larger than the second largest, (ii) the initial version of the license was adopted when there were just a few tenths of nodes, thus, the idea of the need of a formal regulation was introduced from a very early stage, (iii) several CNs, many inspired by guifi.net, have unsuccessfully tried to adopt a similar license when they were already accounting for several hundred nodes; all of them have failed because the number of participants was too high to be able to achieve a consensus on such radical matter. The license has been instrumental to ensure access to the collective infrastructure and ensure participation rights in the production and governance of the CN. It has also enabled its growth.

Diverse participation. As a result of the particular nature of the resource that it is crowdsourced in CNs (i.e. a physical infrastructure), as already discussed broadly, the balance in participation of the three groups identified in Section 2 is crucial to the proper implementation and development of the project due to their specific and irreplaceable roles. In summary, the volunteers have the responsibility to guarantee the project neutrality and its independence, boost creativity and innovation, maintain the DIY spirit and keep the consumers rights; the professionals must supply goods and services because the are responsible to cover the market demand and, for their own interest, they have to rise the funds to maintain the whole ecosystem; the Public Administrations are responsible for the public resources (access to road ducts, poles, etc.), including the network infrastructure, and using it to satisfy their own telecommunication needs.

\footnotetext{
${ }^{55}$ http://www.idescat.cat/pub/?id=ticll13\&lang=en

${ }^{56}$ http : //www . idescat . cat/pub/?id=ticll13\&n=2.4.2\&lang=en

${ }^{57}$ As stated in Section 4, guifi.net presence in Selva is negligible.
} 
The infrastructure as common pool resource. The commons as the most suitable and most effective resource management principle known that guides the life and development of the community.

Effective tools for participation and coordination. They are essential to put in practice the theoretical framework. Tools around open data, procedures, automation and coordination tools help to lower the barrier of access to the infrastructure and to participation in its social production. They reduce the cost of decision making and of action, and are imperative for transparency and accountability. They are also critical for the expansion of the CN. Therefore they must be constantly refined.

Multi-level organisation. A large and complex network requires a multi-level structure for feedback and interactions at many local communities that are coordinated by a second level organisation, such as the guifi.net Foundation, that also interacts with external agents.

Leadership/stewardship. The whole process is very innovative and therefore, due to its open nature, susceptible to deviations. Clear ideas and strong leadership has shown to very effective to stop useless discussions and to isolate disturbing people. Nonetheless, the stewardship must always be reasonable, inclusive and accountable. The higher the organisation level the more important.

Balance effort between development of support tools and network deployment. The main goal and the way to keep the project alive is to deploy network infrastructure and to maintain it operational. Obviously, to accomplish it a full set of tools, many of them discussed in this paper, must be in place. Nonetheless it is crucial to balance the efforts spent in building this enabling infrastructure and those spent in fieldwork. Unfortunately we have witnessed many projects that have failed due to excessive efforts in one of the two aspects leaving the other unattended. Our general recommendation is to take any opportunity to deploy new infrastructure and to solve the problems as they appear (do not forget that the value of the network increases with each new node).

Society engagement. There are a number of reasons to start a CN project. The most frequent ones are experimentation and research by a bunch of highly skilled technical enthusiasts. However the CNs of this kind we know haven't been able to engage the society because these motivations are not appealing to the public in general, and thus, these networks have remained as marginal projects. On the contrary, guifi.net has been envisaged as a production network since the beginning, and thus, has attracted the attention of many people who have found in it an opportunity to solve their connectivity problems. Once they have understood the social value of the proposition, some of them have become very active contributors.

\section{Future work}

Even though the guifi.net project development is extremely positive, as already discussed, it is nonetheless true that it must keep evolving to face the challenges of a globalised context. The inadequate and expensive services of the conventional ISPs has been and remains an opportunity for entrepreneurs to established a foothold in the telecommunications market. However, this market niche is expected to be significantly reduced in the coming years as a result of the modernisation policies that conventional ISPs are implementing. The project as a whole must take the opportunity of this time window to consolidate its position in the market by deploying as much infrastructure as possible, as well as by developing differentiating products which, commercialised by the professionals, since competition based only in price will not be attainable. At ISP level, a right balance between the economy of scale and tailored products is needed. On the one hand, aggregation of customers is an evident strategy for costs reduction, but on the other hand, customised service offerings have shown to be highly appreciated, specially by SMEs. At regional level, the collaboration among ISPs must continue and even be increased to strengthen the project and to continue benefiting from demand aggregation. Initiatives such the development of a regional Exchange Point governed by the guifi.net principles (the CommonsIX) promoted by the Foundation are well aligned to this goal.

Internationalisation is a stimulating challenge with many opportunities. The benefits of the adoption of the guifi.net framework by other communities, that is to say new people with new skills and new ideas, 
with a need to adapt the framework to different realities, with contributions to the formalisation and modularisation processes, etc. would significantly enhance the model if the adopter were from a different state due to regulatory, language, etc. challenges. For instance, many CNs have shown interest in the CNL. However they object that it is too dependent of the Spanish legal framework. Working with a different state adopter would bring the opportunity to decouple global matters from the local specifics. This way, for instance, the CNL could be split into parts, the first to be shared with all the adopters, thus, setting the collaboration framework, and the second tailored for each specific CN to address its local needs. Following the multi-level organisation approach discussed in Section 6, this process would bring the opportunity in this process to create a higher-level (international) organisation to coordinate the CNs and take care of the global matters. The internationalisation process would also contribute to crate awareness of the social value of the commons model for the network infrastructure but for others cases as well.

Internally, the growth of the guifi.net project entails interesting challenges. At social level, for instance, the community of contributors is about to reach a size were they will not know each other easily. This situation will test the tools and social resources developed and is very likely to involve changes. Technically, the IPv4 exhaustion is a major challenge for the community as well as the technological obsolescence of hardware and software.

\section{Conclusions}

Community networks, neutral and open crowdsourced local computer network infrastructures, are a successful model developed in at least the last 10 years, with guifi.net as a success story. The guifi.net community has created and developed a methodology based on commons management principle that has scaled up and has become sustainable by being open and neutral to diverse technological choices, to traffic, and to participants, including volunteers, professionals and public administrations.

guifi.net has evolved to accommodate growth throughout the collective development and usage of tools by the community for coordination, including the software tools for communication, network planning and management, organisational tools such as the community license, the foundation, collaboration agreements, conflict resolution, cost compensation, and social tools to have local meetings and remote coordination on many diverse topics. The result is a healthy community of more than 13,000 registered participants, and a network infrastructure of more than 40,000 declared nodes with more than 27,000 operational, and a total length of around 50,000 Km of links, connected to the global Internet.

Based our experience and findings we claim that 1) self-organized and self-governed communities that can design and implement systems are attainable, and 2) contrary to the trend of privatising public infrastructures, such as the telephone network, we claim the opportunity for transformation and development of network infrastructures held in commons. The guifinet case is an evidence that infrastructures can be effectively managed as a commons, and in fact, the guifi.net case has enough differences, complexity, coherence and completeness that may deserve its own specific model, the guifi.net model. This model of telecommunications infrastructures, compared to conventional models, is socially, economically and environmentally more effective in its context: socially because it is based on the non-discriminatory and open access principles which empowers people and preserves the infrastructure's sovereignty; economically and environmentally because the sharing paradigm on which it is based, the common pool resource, maximises the utilisation of the resources; and that the model shows to scale well.

Future work is required to address and resolve the challenges from regional expansion, replication and internationalisation, and even the application to other infrastructures.

\section{Acknowledgement}

This work is supported by European Community Framework Programme 7, FIRE Initiative projects "Community Networks Testbed for the Future Internet" (CONFINE), FP7-288535, and "A Community networking Cloud in a box" (CLOMMUNITY), FP7-317879. 


\section{References}

[1] J. Avonts, B. Braem, C. Blondia, A Questionnaire based Examination of Community Networksdoi:10.5281/zenodo.7450. URL \{http://dx.doi.org/10.5281/zenodo.7450\}

[2] D. Thapa, O. Saebo, Demystifying the possibilities of ict4d in the mountain regions of nepal, in: System Sciences (HICSS), 2011 44th Hawaii International Conference on, 2011, pp. 1-10. doi:10.1109/HICSS.2011.142.

[3] B. Braem, R. Baig Viñas, A. L. Kaplan, A. Neumann, I. Vilata i Balaguer, B. Tatum, M. Matson, C. Blondia, C. Barz, H. Rogge, F. Freitag, L. Navarro, J. Bonicioli, S. Papathanasiou, P. Escrich, A case for research with and on community networks, ACM SIGCOMM Computer Communication Review 43 (3) (2013) 68-73. doi:10.1145/2500098.2500108. URL http://dl.acm.org/citation. cfm?doid=2500098.2500108

[4] L. Maccari, An analysis of the ninux wireless community network, in: Wireless and Mobile Computing, Networking and Communications (WiMob), 2013 IEEE 9th International Conference on, 2013, pp. 1-7. doi:10.1109/WiMOB.2013.6673332.

[5] L. Cerda-Alabern, On the topology characterization of guifinet, in: Proceedings of the 2012 IEEE 8th International Conference on Wireless and Mobile Computing, Networking and Communications (WiMob), WIMOB '12, IEEE Computer Society, Washington, DC, USA, 2012, pp. 389-396. doi:10.1109/WiMOB.2012.6379103. URL http://dx.doi.org/10.1109/WiMOB.2012.6379103

[6] D. Vega, L. Cerda-Alabern, L. Navarro, R. Meseguer, Topology patterns of a community network: Guifi.net, in: Wireless and Mobile Computing, Networking and Communications (WiMob), 2012 IEEE 8th International Conference on, 2012, pp. 612-619. doi:10.1109/WiMOB.2012.6379139.

[7] E. Ostrom, Governing the commons: the evolution of institutions for collective action, Cambridge University Press, 1990. URL http://www.cambridge.org/us/academic/subjects/politics-international-relations/political-economy/ governing-commons-evolution-institutions-collective-action

[8] G. Hardin, The tragedy of the commons, Science 162 (1968) 1243-1248. URL http://www.sciencemag.org/cgi/reprint/162/3859/1243.pdf

[9] D. Vega, R. Meseguer, F. Freitag, Analysis of the social effort in multiplex participatory networks, in: J. Altmann, K. Vanmechelen, O. Rana (Eds.), Proceedings of the 11th International Conference on Economics of Grids, Clouds, Systems and Services, GECON '14, Springer International Publishing, 2014.

[10] Statistical Institute of Catalonia, Territorial statistics of information and communication technologies in households (2013). URL http://www.idescat. cat/novetats/?id=1724\&lang=en 